\title{
Seroprevalence and risk factors for Toxoplasmosis in HIV infected and non-infected individuals in Bahir Dar, Northwest Ethiopia
}

\author{
Fisseha Walle ${ }^{1}$, Nigatu Kebede ${ }^{2,3^{*}}$, Aster Tsegaye $^{4}$ and Tesfu Kassa ${ }^{2^{*}}$
}

\begin{abstract}
Background: Toxoplasmosis, a zoonotic disease distributed worldwide, is an infection caused by the ubiquitous obligatory intracellular coccidian protozoan organism, Toxoplasma gondii. It is a major public health concern because the disease is serious in terms of mortality or physical and /or psychological sequellae in patients with HIV disease. The aim of the study was to assess the seroprevalence of Toxoplasma gondii lgG and IgM antibodies and associated risk factors in HIV infected and non-infected individuals attending Felege Hiwot referral hospital, Bahir Dar, Northwest Ethiopia.

Methods: A cross sectional study was conducted at Felege Hiwot referral hospital, Bahir Dar, Amhara National Regional State. Venous blood samples were collected from 103 HIV infected pre anti-retroviral therapy patients at Felege Hiwot referral hospital and 101 HIV negative apparently healthy voluntary blood donors at the blood bank. Serum samples were analyzed for anti-Toxoplasma gondii lgG and IgM antibodies using a commercially available ELISA kit. Socio-demographic and associated risk factors for Toxoplasmosis from each individual were also obtained and the data was analyzed using SPSS version 18.
\end{abstract}

Results: Of the examined HIV seropositive individuals, 87.4\% (90/103) and 10.7\% (11/103) were positive for anti-T. gondii IgG and IgM antibodies, respectively. Multivariate analysis using logistic regression showed that anti-T. gondii seropositivity was independently significantly associated with undercooked or raw meat consumption (adjusted $\mathrm{OR}=5.73,95 \% \mathrm{Cl}=1.35-24.39 ; \mathrm{P}=0.02$ ) and having contact with cat (adjusted $\mathrm{OR}=4.29,95 \% \mathrm{Cl}=1.08-16.94 ; \mathrm{P}=0.04$ ) in HIV positive individuals. In HIV negative apparently healthy blood donors, prevalence of anti-T. gondii antibodies were $70.29 \%$ and $2.97 \%$ for $\operatorname{lgG}$ and $\operatorname{lgM}$, respectively. Multivariate analysis showed that undercooked or raw meat consumption (adjusted $\mathrm{OR}=6.45,95 \% \mathrm{Cl}=2.16-19.28 ; \mathrm{p}=0.001$ ) and $\operatorname{sex}(\mathrm{OR}=6.79,95 \% \mathrm{Cl}=2.14-21.60 ; \mathrm{p}=0.001$ ) were independently significantly associated with anti-T. gondii lgG seropositivity, with a significantly higher number of males affected than females.

Conclusion: The present findings showed a high sero-prevalence of anti-T. gondii antibodies in HIV infected pre-ART and HIV non-infected apparently healthy blood donors in Bahir Dar. Consumption of undercooked or raw meat might greatly contribute towards acquiring T. gondii infection in HIV infected pre-ART and HIV non-infected apparently healthy blood donors. It may be appropriate to include routine serological screening test for determination of anti-T. gondii antibodies in HIV infected pre-ART individuals and HIV negative apparently healthy blood donors. In addition, health education towards avoiding eating undercooked and raw meat, and avoiding contact with cats were recommended.

Keywords: Toxoplasmosis, Toxoplasma gondii, IgG, IgM, HIV, Seroprevalence

\footnotetext{
* Correspondence: nigatukebede@yahoo.com; tesfuk@yahoo.com

${ }^{2}$ Aklilu Lemma Institute of Pathobiology, Addis Ababa University, Addis

Ababa, Ethiopia

${ }^{3}$ Department of Pathology, College of Medicine, Ohio State University,

Columbus, OH 43210, USA

Full list of author information is available at the end of the article
}

\section{Biomed Central}

(c) 2013 Walle et al.; licensee BioMed Central Ltd. This is an Open Access article distributed under the terms of the Creative Commons Attribution License (http://creativecommons.org/licenses/by/2.0), which permits unrestricted use, distribution, and reproduction in any medium, provided the original work is properly cited. 


\section{Background}

Toxoplasmosis is a globally distributed zoonosis [1] caused by the ubiquitous obligatory intracellular coccidian protozoan organism, Toxoplasma gondii that infects a wide range of animals, man and birds [2,3]. T. gondii is an opportunistic parasitic infection in immune compromised hosts $[4,5]$ and estimates indicate that up to one third of the world's human population is infected [6]. Prevalence of the infection varies widely, depending on social and cultural habits, geographic factors, climate, and transmission route. It has been reported that the prevalence is higher in warm and humid areas [7]. The parasite causes chronic infection in adults and is present in an estimated $22.5 \%$ of people older than 12 in the United States [8] and up to $90 \%$ of the population in other regions of the world [9].

$T$. gondii is transmitted to humans by eating raw or inadequately cooked infected meat [10]; through ingestion of oocysts that cats have passed in their feces and women can transmit the infection transplacentally to their unborn fetus. Other infection pathways are transfusion, transplantation and direct contamination [11]. In adults, the incubation period for $T$. gondii infection ranges from 10 to 23 days [12].

Toxoplasmosis is a major public health concern because the disease is serious in terms of mortality or physical and /or psychological sequellae in patients with HIV disease [13]. In the majority of normal, healthy (immune competent) subjects, infection is asymptomatic $[7,14]$ and frequently results in the chronic persistence of cysts within host tissues; the cysts normally lie dormant, probably for life [14]. But, in immune compromised states such as in HIV infections, subjects are at risk of developing acute toxoplasmosis due to reactivation of the organism if their CD4+ T-cell count decreases below 200 cells $/ \mu \mathrm{L}[15,16]$. Since the pandemic of HIV infection has spread throughout the world, toxoplasmosis has been implicated as one of the most important opportunistic infections in HIV/AIDS patients [17-19]. Moreover, in up to $10 \%$ of HIV infected immune competent individuals, it causes cervical lymphadenopathy or ocular disease [19].

In the immunocompromised patients, diseases due to $T$. gondii are generally considered to represent reactivation of latent infection [20]. Detection and monitoring of anti-Toxoplasma antibodies are of a great interest in HIV-infected patients. Ethiopia is one of the high HIV epidemic countries [21] with approximately 1.5 million people infected and living with HIV/AIDS. About 5-7\% of patients live in and around Bahir Dar and its neighboring areas. However, the Toxoplasmosis serologic status and risk factors of infection among HIV-infected patients and HIV non-infected apparently healthy individuals remain unknown. Therefore, this study aimed to determine the seroprevalence of anti-T. gondii IgG and IgM antibodies in HIV infected and non-infected individuals and to identify the possible risk factors associated with toxoplasmosis in Bahir Dar, northwest Ethiopia.

\section{Methods}

\section{Study area and study subjects}

A cross sectional study was conducted to determine the seroprevalence and risk factors of toxoplasmosis in HIV infected and non-infected individuals at Felege Hiwot referral hospital, Bahir Dar, Amhara National Regional State, northwest Ethiopia. Bahir Dar is the capital of Amhara National Regional state, located approximately $578 \mathrm{~km}$ Northwest of Addis Ababa, having a latitude and longitude of $11^{\circ} 36^{\prime} \mathrm{N} 37^{\circ} 23^{\prime} \mathrm{E} 11.6^{\circ} \mathrm{N} 37.383^{\circ} \mathrm{E} 11.6$; 37.383 coordinates and an elevation of 1840 meters above sea level. Based on the 2007 Census conducted by the Central Statistical Agency of Ethiopia (CSA), this city has a total human population of 221,991 [22].

The study participants were individuals who visited the hospital to know their HIV sero-status and to donate blood for their families. Thus, the study subjects were HIV sero-positive pre-ART individuals attending the preART clinic of Felege Hiwot referral hospital (Group1), and HIV sero-negative apparently healthy adults who came to the hospital for blood donation (Group 2). The convenient sampling method was followed.

Inclusion criteria of the study subjects in Group 1 were: 1) HIV sero-positive ART naive individuals attending the pre-ART clinic for further management; 2) aged 18 years and older; 3) not taking chemoprophylaxis for toxoplasmosis; and in Group 2 were: 1) voluntary blood donors (HIV, HCV, HBs Ag and Treponema pallidum seronegatives); 2) aged 18-55 years; in both cases individuals who accepted to participate in the study were considered.

\section{Data collection}

Five milliliters of venous blood without anticoagulant was aseptically collected from 103 HIV positive ART naive and 101 HIV negative apparently healthy voluntary blood donors at Felege Hiwot referral hospital pre-ART and blood bank laboratories, respectively. Collected blood samples were transported immediately to Bahir Dar Regional Health Research Laboratory. In the laboratory serum was separated, labeled and stored at $-20^{\circ} \mathrm{C}$ until use.

Using a pretested questionnaire, data on sociodemographic characteristics and associated risk factors were collected from all study participants.

\section{Serological assays}

Serum samples were screened for anti-T. gondii IgG and IgM antibodies by ELISA using "Toxoplasma IgG and IGM" kit (Human, GmbH.65205 Wiesbaden-Biochemical Diagnostic, Germany) according to the manufacturers' instructions. Positive and negative controls were used with each series of anti T. gondii IgG/IgM test (Human, 
Germany); results were obtained by comparison with a cut-off value measured at $450 \mathrm{~nm}$ absorbance.

\section{Ethical approval}

Ethical clearance to conduct the study was obtained from Aklilu Lemma Institute of Pathobiology (ALIPB), Addis Ababa University (AAU) and Amhara National Regional State Health Bureau (ANRSHB). The purpose and procedures of the study were explained and a written informed consent was obtained from all study participants. Study participants with positive test result for toxoplasmosis were treated following standard protocols at Felege Hiwot referral hospital, following the FMOH (Federal Ministry of Health), guidelines [23].

\section{Statistical analysis}

Data was entered into MS Excel, cleaned and analyzed using SPSS software, with Version 18.0. Pearson Chisquare, Odds Ratio and 95\% confidence interval were used for group comparison and association of variables. $P$ values were determined and taken as a level of significance when found less than 0.05 .

\section{Results}

The overall prevalence of anti- $T$. gondii IgG antibodies in HIV positives pre-ART individuals and apparently healthy blood donors were found to be $87.4 \%$ (90/103) and 70.29\% (71/101), respectively. The difference between the two groups in anti- $T$. gondii IgG seropositivity was statistically significant $(\mathrm{p}=0.003)$. Similarly, the overall anti- $T$. gondii IgM seropositivity was $10 \%(11 / 103)$ among HIV infected Pre ART and $2.97 \%(3 / 101)$ in HIV non-infected study participants; the difference was statistically significant $(\mathrm{p}=0.02)$. Overall, the prevalence of anti-T. gondii antibodies in HIV positives pre-ART individuals was significantly higher than HIV non-infected apparently healthy blood donors (Tables 1,2).

In HIV infected pre-ART individuals studied, where the majority reported having contact with cats 72/103 (69.9\%) and the habit of eating raw or undercooked meat 86/103 (83.5\%), the bivariate analysis showed a significant association between these factors and seropositivity to anti- $T$. gondii IgG antibodies (Table 1). No significant association was observed between seropositivity for anti-T. Gondii IgG antibodies and educational status, eating unwashed raw vegetables or fruits, residence (urban versus rural inhabitants). In addition, the prevalence of anti- $T$. gondii IgG, among the HIV positive pre-ART individuals was not statistically influenced by the sex and age categories tested. In the study there were only three individuals with history of blood transfusion, and all of them were HIV positive.

In HIV infected pre-ART individuals, no statistically significant association was detected between anti-T. gondii IgM seropositivity and all the risk factors evaluated.
In HIV non-infected apparently healthy voluntary blood donors, among the demographic and other risk factors studied, consumption of undercooked or raw meat and sex of the individual was significantly associated with anti-T. gondii IgG seropositivity. The rate of anti-T. gondii IgG seropositivity was significantly higher in males than females, and in those eating raw or undercooked meat compared to those who did not (Table 2).

As shown in Table 3, multivariate analysis using logistic regression showed that undercooked or raw meat consumption (adjusted $\mathrm{OR}=5.73,95 \% \mathrm{CI}=1.35-24.39$, $\mathrm{p}=0.02$ ) and having contact with cat (adjusted $\mathrm{OR}=4.29$, 95\% CI $=1.08-16.94, \mathrm{p}=0.04$ ) were independently associated with anti Toxoplasma IgG seropositivity in HIV infected patients. Whereas in HIV uninfected participants, undercooked or raw meat consumption (adjusted $\mathrm{OR}=6.45,95 \% \mathrm{CI}=2.16-19.28 ; \mathrm{p}=0.001)$ and being male (adjusted OR=6.79, 95\% CI=2.14-21.60, $\mathrm{p}=0.001$ ) were independently significantly associated with anti- $T$. gondii IgG seropositivity (Table 4). In addition, being in the age group 21-30 was significantly associated with $T$. gondii IgG seropositivity compared to the reference age group 18-20 years (adjusted OR 5.58, 95\% CI=1.62-19.29, $\mathrm{p}=0.01)$.

\section{Discussion}

Toxoplasmosis refers to the disease caused by $T$. gondii [24]. In the present study Toxoplasma specific IgG and IgM antibody levels were analyzed using ELISA, one of the standard procedures for detection of antibodies [18]. Detection of both IgG and IgM simultaneously helps establishing exposure to $T$. gondii and the chronological status of such exposure. In the present study the prevalence rate of anti- $T$. gondii IgG antibodies in HIV positive pre-ART individuals was significantly higher than in HIV negative blood donors $(87.4 \%$ versus $70.29 \%, \mathrm{P}=0.003)$. Similar finding of significantly higher Toxoplasma seropositivity in HIV infected individuals than in HIV-uninfected people was also demonstrated in Addis Ababa [25]. The finding of significant difference between HIV infected and non-infected individuals also agrees with studies done in Bamako, 60\% versus 21\% [26] and in Nigeria 54\% versus $37.5 \%$ [27]. These differences might be attributed to the reactivation of latent infection/tissue toxoplasmosis when the host immunity is compromised (reduced cellular immunity) in HIV patients [28]. In addition, variability in results can be due to differences in age among the study groups and differing lifestyles and geographical conditions. In our case, HIV infected patients were older compared to the HIV negative counterparts (median age 23 versus 34 years, $\mathrm{p}=0.000$ ).

The overall finding of a high seroprevalence of IgG in HIV positive pre-ART individuals was comparable with the study done in Akaki town, suburban of Addis Ababa, 
Table 1 Seroprevalence of Toxoplasma infection in HIV infected pre-ART individuals according to socio demographic and other risk factors

\begin{tabular}{|c|c|c|c|c|c|}
\hline Variable & Frequency (\%) & IgG +ve (\%) & P value ${ }^{*}$ & $\lg M+v e(\%)$ & $\mathrm{P}$ value \\
\hline Age in years & & & 0.45 & & 0.78 \\
\hline $18-20$ & $3(2.9)$ & $3(100)$ & & $0(0.0)$ & \\
\hline $21-30$ & $43(41.8)$ & $35(81.4)$ & & $4(9.3)$ & \\
\hline $31-40$ & $31(30.1)$ & $28(90.3)$ & & $3(9.7)$ & \\
\hline $41-55$ & $26(25.2)$ & $24(92.3)$ & & $4(15.4)$ & \\
\hline Sex & & & 0.39 & & 0.70 \\
\hline $\bar{M}$ & $43(41.7)$ & $39(90.7)$ & & $4(9.3)$ & \\
\hline $\mathrm{F}$ & $60(58.3)$ & $51(85.0)$ & & $7(11.7)$ & \\
\hline Place of residence & & & 0.29 & & 0.75 \\
\hline Urban & $96(93.2)$ & $83(86.5)$ & & $10(10.4)$ & \\
\hline Rural & $7(6.8)$ & $7(100)$ & & $1(14.3)$ & \\
\hline Education & & & 0.20 & & 0.68 \\
\hline Literate & $71(68.9)$ & $64(90.1)$ & & $7(9.9)$ & \\
\hline Illiterate & $32(31.1)$ & $26(81.3)$ & & $4(12.5)$ & \\
\hline History of blood transfusion & & & 0.27 & & 0.19 \\
\hline$\overline{\text { Yes }}$ & $3(2.9)$ & $2(66.7)$ & & $1(33.3)$ & \\
\hline No & $100(97.1)$ & $88(88.0)$ & & $10(10.0)$ & \\
\hline Contact with cat & & & 0.04 & & 0.83 \\
\hline Yes & $72(69.9)$ & $66(91.7)$ & & $8(11.1)$ & \\
\hline No & $31(30.1)$ & $24(77.4)$ & & $3(9.7)$ & \\
\hline Eating undercooked or raw meat & & & 0.02 & & 0.31 \\
\hline$\overline{\text { Yes }}$ & $86(83.5)$ & $78(90.7)$ & & $8(9.3)$ & \\
\hline No & $17(16.5)$ & 12(70.6) & & $3(17.7)$ & \\
\hline Eating unwashed raw vegetables or fruits & & & 0.85 & & 0.82 \\
\hline$\overline{\text { Yes }}$ & $50(48.5)$ & $44(88.0)$ & & $6(12.0)$ & \\
\hline No & $53(51.5)$ & $46(86.8)$ & & $5(9.4)$ & \\
\hline Total & 103(100) & $90(87.4)$ & & $11(10.7)$ & \\
\hline
\end{tabular}

*P values were calculated using Chi square test.

in which sera were screened for anti-Toxoplasma IgG antibodies using the Sabin-Feldman test and $80 \%$ seroprevalence was reported [29]. Our finding is also consistent with a Venezuelan study which demonstrated $85 \%$ prevalence of anti- $T$. gondii IgG antibody in the HIV-positive adult population [15]. However, our result was much higher than other studies as in Johannesburg $8 \%$ [30]. It also differs from a study done in Iran among HIV/AIDs patients which reported prevalence of $58 \%$ [31]. The observed differences in prevalence of anti- $T$. gondii antibodies could be due to differences in geographical distribution and/ or possible risk factors and socioeconomic conditions [32] contributing to acquiring the infection.

In the present study, anti-T. gondii IgM seropositivity rate was $10.7 \%$ in HIV infected pre-ART individuals. A similar study in India reported 6\% anti-Toxoplasma IgM positivity using double sandwich ELISA [14]. The consumption of undercooked or raw meat and contact with cat were found to be risk factors for the presence of anti-T. gondii IgG in HIV infected pre-ART individuals. Similar results were demonstrated by studies done in Nazaret town, Ethiopia [3] and at Lagos University teaching hospital, Nigeria [27]. On the other hand, no significant association was identified between the history of blood transfusion and anti-T. gondii seropositivity. It is worth mentioning that the number of participants with a history of blood transfusion was only three and all of them were HIV positive. Nonetheless, a similar study in Malaysia has documented the absence of a significant association between a history of blood transfusion and T. gondii seropositivity [24]. Beef, lamb and chicken are eaten in the study area. In the nation raw meat dishes such as "Kitfo" and "kourt" are most favored by the society and eaten raw or lightly cooked. However, HIV positive individuals are advised to eat cooked meat to minimize persistent immune activation as a result of tapeworms and or other secondary 
Table 2 Seroprevalence of Toxoplasma infection in HIV non-infected apparently healthy blood donors according to socio demographic and other risk factors

\begin{tabular}{|c|c|c|c|c|c|}
\hline Variable & Frequency (\%) & lgG +ve(\%) & P value & $\lg M+v e(\%)$ & $\mathrm{P}$ value \\
\hline Age in years & & & 0.06 & & 0.52 \\
\hline $18-20$ & $29(28.7)$ & $15(51.7)$ & & $1(3.5)$ & \\
\hline $21-30$ & $53(52.5)$ & $41(77.4)$ & & 1(1.9) & \\
\hline $31-40$ & $9(8.9)$ & $8(88.9)$ & & $0(0.0)$ & \\
\hline $41-55$ & 10(9.9) & $7(70.0)$ & & $1(10.0)$ & \\
\hline Sex & & & 0.001 & & 0.54 \\
\hline$M$ & $50(49.5)$ & $44(88.0)$ & & $2(4.0)$ & \\
\hline $\mathrm{F}$ & $51(50.5)$ & $27(52.9)$ & & $1(2.0)$ & \\
\hline Place of residence & & & 0.88 & & 0.25 \\
\hline Urban & $67(66.3)$ & $46(68.7)$ & & $1(1.5)$ & \\
\hline Rural & $34(33.7)$ & $25(73.5)$ & & $2(5.9)$ & \\
\hline Education & & & 0.86 & & 0.23 \\
\hline Literate & $66(65.4)$ & $46(69.7)$ & & $1(1.5)$ & \\
\hline Illiterate & $35(34.7)$ & $25(71.4)$ & & $2(5.7)$ & \\
\hline \multicolumn{6}{|l|}{ History of blood transfusion } \\
\hline Yes & 0 & 0 & & $0(0.0)$ & \\
\hline No & $101(100)$ & $71(70.3)$ & & $3(3.0)$ & \\
\hline Contact with cat & & & 0.81 & & 0.95 \\
\hline Yes & $69(68.3)$ & $48(69.6)$ & & $2(2.9)$ & \\
\hline No & $32(31.7)$ & 23(71.9) & & $1(3.1)$ & \\
\hline Eating undercooked or raw meat & & & 0.001 & & 0.17 \\
\hline$\overline{\text { Yes }}$ & $63(62.4)$ & $53(84.1)$ & & $3(4.8)$ & \\
\hline No & $38(37.6)$ & $18(47.4)$ & & $0(0.0)$ & \\
\hline Eating unwashed raw vegetables or fruits & & & 0.17 & & 0.82 \\
\hline Yes & $61(60.4)$ & $46(75.4)$ & & 2(3.3) & \\
\hline No & $40(39.6)$ & $25(62.5)$ & & $1(2.5)$ & \\
\hline Total & $101(100 \%)$ & $71(70.29 \%)$ & & $3 / 101(2.97)$ & \\
\hline
\end{tabular}

*P values were calculated using Chi square test.

Table 3 Multivariate analysis of selected characteristics of 103 HIV infected Pre-ART individuals and their association with anti-IgG to $T$. gondii infection

\begin{tabular}{|c|c|c|c|}
\hline Characteristics $^{a}$ & $\begin{array}{l}\text { Adjusted } \\
\text { odds ratio }^{b}\end{array}$ & $\begin{array}{l}95 \% \text { confidence } \\
\text { interval }\end{array}$ & $P$ value \\
\hline \multicolumn{4}{|l|}{ Education } \\
\hline Literate & 1.31 & $0.35-4.87$ & 0.69 \\
\hline Illiterate & 1 & & \\
\hline \multicolumn{4}{|l|}{ Contact with Cat } \\
\hline Yes & 4.29 & $1.08-16.94$ & 0.04 \\
\hline No & 1 & & \\
\hline \multicolumn{4}{|c|}{ Eating under cooked or raw meat } \\
\hline Yes & 5.73 & $1.35-24.39$ & 0.02 \\
\hline No & 1 & & \\
\hline
\end{tabular}

a The variables included were those with $\mathrm{P} \leq 0.2$ obtained in the bivariate analysis.

${ }^{\mathrm{b}}$ Odds ratio adjusted for variables included in the table. infections through meat as immune activation is one of the mechanism of CD4 depletion. HIV negative individuals consume raw and undercooked favorite meat dishes such as "Kitfo" and "kourt" of the Ethiopians. Pork is not consumed at all in the study area.

According to the present findings, no statistically significant difference was observed among different age groups and inhabitants of rural and urban areas of HIV infected and non-infected study participants, and the associated sero-reactivity of anti- $T$. gondii antibodies. The exception to this is the age group 21-30 in the HIV negatives where individuals are 5.58 times more likely to be seropositive for anti-T. gondii antibodies. This is in agreement with previous studies on the prevalence of anti-T. gondii IgG antibodies from blood donors in Yucatan [33] and seroprevalence of anti-T. gondii antibodies in a healthy population from Slovakia [7]. The prevalence of anti-T. gondii IgG and IgM antibodies in HIV negative blood donors were $70.29 \%$ and $2.97 \%$, 
Table 4 Multivariate analysis of selected characteristics of 101HIVnegative apparently healthy voluntary blood donors and their association with anti-IgG to $T$. gondii infection

\begin{tabular}{llll}
\hline Characteristics $^{\mathbf{a}}$ & $\begin{array}{l}\text { Adjusted odds } \\
\text { ratio }^{\mathbf{b}}\end{array}$ & $\begin{array}{l}\mathbf{9 5 \%} \text { confidence } \\
\text { interval }\end{array}$ & P value \\
\hline Sex & 6.79 & $2.14-21.60$ & 0.001 \\
\hline Male & 1 & & \\
\hline Female & & & 0.01 \\
\hline Age & 1 & $1.62-19.29$ & 0.09 \\
\hline $18-20$ & 5.58 & $0.73-104.47$ & 0.45 \\
\hline $21-30$ & 8.71 & $0.31-14.04$ & \\
\hline $31-40$ & 2.09 & &
\end{tabular}

Eating under cooked or raw meat

\begin{tabular}{llll}
\hline Yes & 6.45 & $2.16-19.28$ & 0.001 \\
\hline
\end{tabular}

No

${ }^{a}$ The variables included were those with $\mathrm{P} \leq 0.2$ obtained in the bivariate analysis.

${ }^{b}$ Odds ratio adjusted for variables included in the table.

respectively. Seroprevalence of IgM that we found was comparable to the $2.4 \%$ and $1.9 \%$ reported from Czech Republic and Mexico blood donors, respectively [34,35]. The present finding of anti- $T$. gondii IgG antibodies in blood donors is consistent with the $75 \%$ prevalence reported from Brazil [36] and 69\% from the Southern Mexican State of Yucatan [33]. Consumption of undercooked or raw meat was found to be a risk factor for the presence of anti-T. gondii IgG in HIV negative individuals. Undercooked meat consumption has been found to be an important factor in parasite transmission in several studies $[18,35]$. A similar finding was also demonstrated as risk factor for toxoplasmosis in studies done in Slovakia [7]. Moreover, prevalence of anti- $T$. gondii IgG from male healthy blood donors was significantly higher than female HIV negative blood donors $(\mathrm{p}=0.001)$.

In the present study no significant association was found between the seroprevalence of toxoplasmosis and different educational status. Similar findings were recorded between anti Toxoplasma IgG antibodies and education level [27] and the infection among pregnant women in Turkey [37].

Generally, IgM antibodies are detectable early after infection and can persist for prolonged times after infection. Therefore, the presence of IgM does not necessarily indicate an acute infection and its presence in subjects with anti $T$. gondii IgG antibodies could indicate a chronic infection [34]. Hence, though we cannot confirm in this study, the finding of sero-positive anti-T. gondii IgM/IgG antibodies suggests the potential risk of parasite transmission by blood transfusion practices.

Findings on the association of HIV and toxoplasmosis seroprevalence are varied in different parts of the world.
Previous studies involving HIV-infected individuals have reported wide variations in $T$. gondii seroprevalence $(3 \%-22 \%)$ [38,39]. Some authors found higher prevalence of $T$. gondii specific IgG in HIV-infected patients compared to non-infected individuals [40,41], whereas others did not find any differences between the two groups [42]. Serologic data provided little information, in extracerebral toxoplasmosis in patients infected with HIV [43]. Previous studies in Ethiopia revealed a higher Toxoplasma seroprevalence in both HIV infected and non-infected individuals that is not statistically significantly different between the two groups [29]. On the other hand, studies from Mozambique [44] found similar higher toxoplasmosis occurrence in the HIV-positive groups as compared to HIV-negative groups that according to the authors could be ascribed to common or associated risk factors for both infections, such as exposure to both sexual contacts and meat consumption. Several explanations for the interaction between both infections resulting in high Toxoplasma infection in HIV patients have been previously proposed [45]. One possibility is an increase in risky behavior in Toxoplasma infected individuals that leads to increased exposure to HIV infection. Such a change in behavior could be due to parasite-driven personality changes, as described in Toxoplasma-infected individuals by others [46]. Another plausible explanation is that Toxoplasma infection is a marker of exposure to risky social contacts or habits, which correlates with early HIV infection.

Regarding the higher prevalence in males than females, Shimelis et al., [47] observed a statistically significantly higher prevalence rate of Toxoplasma infection in males than females in the bivariate analysis, which disappeared in the multivariate analysis. In our case the difference is maintained in the multivariate model and may be attributed to differences in socialization behavior or environmental exposure of males compared to females.

\section{Conclusion}

In conclusion, the present findings showed a high seroprevalence of anti- $T$. gondii antibodies in HIV infected pre-ART and HIV non-infected apparently healthy blood donors in Bahir Dar. Consumption of undercooked or raw meat and contact with cat might greatly contribute towards acquiring $T$. gondii infection. It may be appropriate to include a routine serological screening test for determination anti-T. gondii antibodies in HIV infected pre ART individuals and HIV negative apparently healthy blood donors. Those HIV infected individuals, positives for anti-T. gondii antibodies should be considered for chemoprophylactic treatment. In addition, health education particularly not to eat undercooked and raw meat, and avoiding contact with cats should be considered. 


\section{Competing interest}

The authors declared that they have no competing interest.

\section{Authors' contributions}

FW conceived the study, undertook statistical analysis and drafted the manuscript. NK, AT and TK initiated the study and made major contributions to the study design and statistical analysis. All authors contributed to the writing of the manuscript and approved the submitted version of the manuscript.

\section{Financial support}

This study was financially supported by Addis Ababa University and additional funds from Amhara National Regional State Health Bureau.

\section{Acknowledgments}

We would like to acknowledge Bahir Dar Regional Health Research Laboratory (BRHRL) for provision of materials. We would also like to forward special thanks to the study participants and those persons who worked in ART and blood bank Laboratories at Felege Hiwot referral hospital for their assistances during sample collections.

\section{Author details}

'Department of Immunology and Hematology, Bahir Dar Regional Health Research Laboratory, Bahir Dar, Ethiopia. ${ }^{2}$ Aklilu Lemma Institute of Pathobiology, Addis Ababa University, Addis Ababa, Ethiopia. ${ }^{3}$ Department of Pathology, College of Medicine, Ohio State University, Columbus, $\mathrm{OH} 43210$, USA. ${ }^{4}$ Department of Medical Laboratory Sciences, Addis Ababa University, Addis Ababa, Ethiopia.

Received: 1 August 2012 Accepted: 4 January 2013

Published: 16 January 2013

\section{References}

1. Tenter AM, Heckeroth AR, Weiss LM: Toxoplasma gondii: from animals to humans. Int J Parasitol 2000, 30:1217-1258.

2. Djurković-Djaković O: Toxoplasmosis and immune suppression. Srp Arh Celok Lek 1998, 126(5-6):197-203.

3. Negash T, Tilahun G, Medhin G: Seroprevalence of Toxoplasma gondii in Nazareth town Ethiopia. East Afr J Public Health 2008, 5(3):211-214.

4. Denkers YE, Gazzinelli TR: Regulation and function of T-cell-mediated immunity during Toxoplasma gondii infection. Clin Microbiol Rev 1998, 11(4):569-588.

5. Ferreira SM, Borges SA: Some aspects of protozoan infections in immuno compromised patients - a review. BioLine Int System 2002, 97(4):443-457.

6. Swai ES, Schoonman L: Seroprevalence of Toxoplasma gondii infection amongst residents of tanga district in north-east Tanzania. Tanz J Hth Res 2009, 11(4):205-209.

7. Studeničová C, Benčaiová G, Holková R: Seroprevalence of Toxoplasma gondii antibodies in a healthy population from Slovakia. Eur J Intern Med 2006, 17:470-473.

8. Jones JL, Kruszon-Moran D, Wilson M, McQuillan G, Navin T, McAuley JB: Toxoplasma gondii infection in the united states: seroprevalence and risk factors. Am J Epidemiol 2001, 154:357-365.

9. Sousa OE, Saenz RE, Frenkel JK: Toxoplasmosis in panama: a 10-year study. AmJTrop Med Hyg 1988, 38:315-322.

10. Dubey JP: Toxoplasmosis. J Am Vet Med Assoc 1994, 205:1593-1598.

11. Galvan Ramirez ML, Rodríguez Pérez LR, Ledesma Agraz SY, Sifuentes ávila LM, Armenta Ruíz AS, Corella DB, Ramírez Fernández BJ, Sanromán RT: Sero epidemiology of toxoplasmosis in high-school students in the metropolitan area of Guadalajara, Jalisco, Mexico. Sci Med 2010, 20(1):59-63

12. Lynfield R, Guerina NG: Toxoplasmosis. Ped Rev 1997, 18:75-83.

13. Elsheikha MH, Azab SM, Abousamra KN, Rahbar HM, Elghannam MD, Raafat D: Seroprevalence of and risk factors for Toxoplasma gondii antibodies among asymptomatic blood donors in Egypt. J Parasitol 2009, 104(6):1471-1476.

14. Malla N, Sengupta C, Dubey ML, Sud A, Dutta U: Antigenaemia and antibody response to toxoplasma gondii in human immuno deficiency virus infected patients. Br J Biomed Sci 2005, 28:104-109.
15. Martinez E, Mago H, Rocha R, Pacheco M: Epidemiological findings and prevalence of Toxoplasma gondii antibodies in HIV-positive patients in a Venezuelan hospital. Valencia Int Conf AIDS 2002, 7-12:14.

16. Jayawardena S, Singh S, Burzyantseva O, Clarke H: Cerebral toxoplasmosis in adult patients with HIV infection. Clin Med J Resid Hosp Physician 2008, 44(7):17-24.

17. Nissapatorn V, Kamarulzaman A, Init I, Tan LH, Rohela M, Norliza A, Chan LL, Latt HM, Anuar AK, Quek KF: Seroepidemiology of toxoplasmosis among HIV- infected patients and healthy blood donors. Med J Malaysia 2002, 57(3):304-310.

18. Montoya JG, Remington JS: Toxoplasma gondii. In Principles and practice of infectious diseases. 5th edition. Edited by Mandell GE, Beneth JE, Dolin R. Odon: Churchill Livingstone; 2000:2858-2888.

19. Walker M, Zunt JR: Parasitic central nervous system infections in immunocompromised hosts. Clin Inf Dis 2005, 40:1005-1015.

20. Machala L, Kodym P, Rozsypal H, Stanková M, Sedlácek D: Recommendation for diagnostics and therapy of toxoplasmosis in persons with HIV infection. Klin Mikrobiol Infekc Lek 2007, 13:248-252.

21. UNAIDS: UNAIDS: world AIDS Day report, 2011. Ethiopia: Impact of HIV/AIDS; 2011. http://www.etharc.org/oromia/resources/kit/ARTInfotoolkit.pdf. Accessed on June 24, 2012

22. Central Statistical Authority of Ethiopia (CSA): Summary and statistical report of the 2007 population census. Population size by age and sex. Federal Democratic Republic of Ethiopia: Population census Commission; 2008

23. Federal Ministry of Health (FMOH): Guidelines for management of opportunistic infections and anti retroviral treatment in adolescents and adults in Ethiopia. Office Federal Ministry of Health: Federal HIV/AIDS Prevention and Control; 2008.

24. Nissapatorn $V$, Abdullah AK: Review on human toxoplasmosis in Malaysia: the past, present and prospective future southeast Asian. J Trop Med Public Health 2004, 35(1):24-30.

25. Shimelis T, Tebeje M, Tadesse E, Tegbaru B, Terefe A: Seroprevalence of latent Toxoplasma gondii infection among HIV- infected and HIV-uninfected people in Addis Ababa Ethiopia: a comparative cross-sectional study. Pak J Biol Sci 2009, published online October 23.

26. Maïga I, Kiemtoré $P$, Tounkara A: Prevalence of anti-toxoplasma antibodies in patients with acquired immunodeficiency syndrome and blood donors in bamako. Bull Soc Pathol Exot 2001, 94(3):268-270.

27. Akanmu AS, Asunkalu VO, Ofomah JN, Olowosenlu FO: Pattern of demographic risk factors in the seroprevalence of anti-Toxoplasma gondii antibodies in HIV infected patients at Lagos university teaching hospital. Nig Q J Hosp Med 2010, 20(1):1-4.

28. Zhou P, Chen Z, Li HL, Zheng H, He S, Lin RQ, Zhu XQ: Toxoplasma gondii infection in humans in china. Parasit Vectors 2011, 4:165.

29. Woldemichael T, Fontanet AL, Sahlu T, Gilis H, Messele T, Yeneneh H, Coutinho RA, Van Gool T: Evaluation of the elke latex agglutination test for anti-Toxoplasma antibodies and seroprevalence of Toxoplasma infection among factory workers in Addis Ababa Ethiopia. Trans $R$ SoC Trop Med Hyg 1998, 92(4):401-403.

30. Hari KR, Modi MR, Mochan AHD, Modi G: Reduced risk of Toxoplasma encephalitis in HIV-infected patients - a prospective study from Gauteng, south Africa. Int J STD AIDS 2007, 18(8):555-558.

31. Davarpanah MA, Mehrabani D, Neirami R, Ghahremanpoor M, Darvishi M: Toxoplasmosis in HIV/AIDs patients in Iran. Iran Red Crescent Med J 2007, 9(1):22-27.

32. Alvarado-Esquivel C, Torres-Castorena A, Liesenfeld O, Estrada-Martínez S, Urbina-álvarez JD: High seroprevalence of Toxoplasma gondii infection in a subset of Mexican patients with work accidents and low socioeconomic status. Parasit Vectors 2012, 5:13.

33. Góngora-Biachi RA, Gonzalez Martinez P, Castro-Sansores C, Alvarez-Moguel R, Pavía-Ruz N, Lara-Perera D, Alonzo-Salomón G, Palacios-Pérez E: Antibodies against Toxoplasma gondii in patients with HIV in Yucatan. Rev Invest Clin 1998, 50(5):419-22.

34. Svobodová V, Literák I: Prevalence of IgM and IgG antibodies to Toxoplasma gondii in blood donors at the Czech republic. Eur J Epidemiol 1998, 14(8):803-805.

35. Alvarado-Esquivel C, Mercado-Suarez FM, Rodringuez-Briones A, Fallad-Torres L, Ayala-Ayala OJ, Nevarez-Piedra JL, Duran-Morales E, Estrada-Martinez S, Liessenfeld O, Marquez AJ: Seroepidemiology of infection with Toxoplasma gondii in health blood donors of Durango, Mexico. BMC Infect Dis 2007, 7:75. 
36. Coelho RA, Kobayashi M, Carvalho J: Prevalence of lgG antibodies specific to Toxoplasma gondii among blood donors in Recife northeast brazil. Rev Inst Med Trop Sao Paulo 2003, 45(4):229-231.

37. Ertug S, Okyay P, Turkmen M, Yuksel H: Seroprevalence and risk factors for Toxoplasma infection among pregnant women in aydi province turkey. BMC Publ Health 2005, 5:66.

38. Grant IH, Gold WM, Rosenblum M, Niedzwieki D, Armstrong D: Toxoplasma gondii serology in HIV infected patients: the development of central nervous system toxoplasmosis in AIDS. AIDS 1990, 4:519-521.

39. Wallace MR, Rossetti RJ, Olson PE: Cats and toxoplasmosis risk in HIV-infected adults. JAMA 1993, 269(1):76-7.

40. Morvan JM, Mambely R, Selekon B, Coumanzi-Malo MF: Toxoplasmosis at the Pasteur institute of Bangui, central African republic (1996-1998): serological data. Bull Soc Pathol Exot 1999, 92:157-160.

41. Galván-Ramírez ML, Troyo R, Roman S, Calvillo-Sanchez C, Bernal-Redondo R, Gómez F: A systematic review and meta-analysis of Toxoplasma gondii infection among the Mexican population. Parasit Vectors 2012, 5:271.

42. Sýkora J, Zástěra M, Stanková M: Toxoplasmic antibodies in sera of HIV-infected persons. Folia Parasitol (Praha) 1992, 39:177-180.

43. Rabaud C, May T, Amiel C, Katlama C, Leport C, Ambroise-Thomas P, Canton P: Extracerebral toxoplasmosis in patients infected with HIV. A French national survey. Medicine (Baltimore) 1994, 73:306.

44. Sitoe SP, Rafael $B$, Meireles $L R$, Andrade HF, Thompson R: Preliminary report of HIV and Toxoplasma gondii occurrence in pregnant women from Mozambique. Rev Inst Med Trop Sao Paulo 2010, 52(6):291-2295.

45. Lin DS, Bowman DD: Toxoplasma gondii: an AIDS enhancing cofactor. Medical Hypotheses 1992, 39(2):140-142.

46. Fleger J, Kova S, Kodym P, Frgnta O: Induction of changes in human behaviour by the parasitic protozoan Toxoplasma gondii. Parasitol 1996, 113:49-54.

47. Shimelis T, Tebeje M, Tadesse E, Tegbaru B, Terefe A: Sero-prevalence of latent Toxoplasma gondii infection among HIV-infected and HIV-uninfected people in Addis Ababa Ethiopia: a comparative cross-sectional study. BMC Res Notes 2009, 2:213.

doi:10.1186/1756-3305-6-15

Cite this article as: Walle et al: Seroprevalence and risk factors for

Toxoplasmosis in HIV infected and non-infected individuals in Bahir Dar, Northwest Ethiopia. Parasites \& Vectors 2013 6:15.

\section{Submit your next manuscript to BioMed Central and take full advantage of:}

- Convenient online submission

- Thorough peer review

- No space constraints or color figure charges

- Immediate publication on acceptance

- Inclusion in PubMed, CAS, Scopus and Google Scholar

- Research which is freely available for redistribution 